\title{
Influência das pontas excessivas de esmalte dentário na digestibilidade e nutrientes de dietas de eqüinos
}

\author{
[Influence of excessive enamel points on nutrients digestibility in diets of horses] \\ G.M. Pagliosa ${ }^{1}$, G.E.S. Alves $^{1}$ *, R.R. Faleiros ${ }^{1}$, E.O.S. Saliba ${ }^{1}$, I.B.M. Sampaio ${ }^{1}$, \\ T.L.S. Gomes ${ }^{2}$, A.A.O. Gobesso ${ }^{3}$, P. Fantini ${ }^{1}$ \\ ${ }^{1}$ Escola de Veterinária - UFMG \\ Caixa Postal, 567 \\ 30123-970 - Belo Horizonte, MG \\ ${ }^{2}$ Hospital de Eqüinos Salles Gomes, Foz e Associados - Jundiaí, SP \\ ${ }^{3}$ FMVZ-USP - Pirassununga, SP
}

\begin{abstract}
RESUMO
Para avaliar a influência das pontas excessivas de esmalte dentário na digestibilidade dos nutrientes de dietas de eqüinos, utilizaram-se 13 animais alimentados com capim-elefante (Pennisetum purpureum) e ração comercial. Foram analisadas matéria seca, proteína bruta, energia bruta, fibra em detergente neutro, fibra em detergente ácido, hemicelulose e celulose nas fezes antes e duas semanas após o desgaste corretivo das pontas excessivas de esmalte. A digestibilidade aumentou $(\mathrm{P}<0,001)$ em todas as variáveis estudadas após o desgaste corretivo.
\end{abstract}

Palavras-chave: eqüino, pontas excessivas de esmalte, digestibilidade

\begin{abstract}
The influence of excessive enamel points on structural carbohydrates digestibility in horses was evaluated. Thirteen horses were fed on elephant grass (Pennisetum purpureum) and concentrate. Dry matter, crude protein, gross energy, neutral detergent fiber, acid detergent fiber, hemicellulose and cellulose were measured in the feces before and two weeks after floating of the excessive enamel points. The apparent digestibility of all nutrients was increased $(P<0.001)$ after the treatment.
\end{abstract}

Keywords: horse, excessive enamel points, digestibility

\section{INTRODUÇ̃̃O}

O aproveitamento dos carboidratos estruturais depende, em grande parte, da adequada ruptura da barreira físico-química vegetal para exposição do conteúdo de sua membrana celular, o que ocorre principalmente através da trituração durante a mastigação (Akin, 1989). Alterações dentárias podem afetar a biomecânica do ciclo mastigatório (Fig. 1) e prejudicar a adequada trituração dos alimentos. As pontas excessivas de esmalte dentário (PEED) resultam do desgaste dentário anômalo e são capazes de influir negativamente na trituração das forragens e, conseqüentemente, em sua digestibilidade.

Recebido em 29 de abril de 2004

Aceito em 11 de outubro de 2005

*Autor para correspondência (corresponding author)

E-mail: geraldo@vet.ufmg.br 


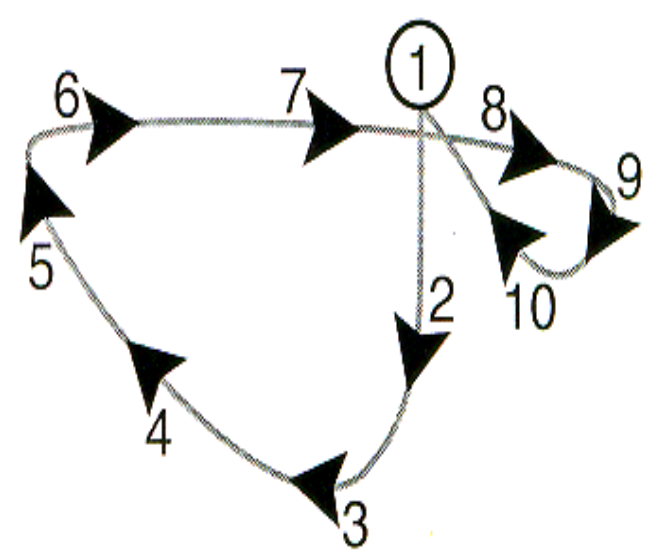

Figura 1. Esquema das fases do ciclo mastigatório dos eqüinos definidas de acordo com o movimento mandibular, representado pelo traço contínuo. Os números de 1 a 3 representam a fase de abertura; 4 e 5, a fase de fechamento; de 6 a 9, a fase de impacto e atrito (IA); e o número 10 , a fase de retorno.

Fonte: adaptado de Baker (2002).

As PEED são o distúrbio mais abordado na prática da odontologia eqüina, com incidência de 44 a $72 \%$, sendo mais expressivas em eqüinos de até nove anos de idade devido à rizogênese dos dentes permanentes (Dixon, 2000; Dixon et al., 2000; Brigham e Ducanson, 2000; Baker, 2002).

As PEED são uma conseqüência das mudanças no hábito alimentar ocorridas após a domesticação. A adição de alimento concentrado e a menor oferta de forragem diminuíram o tempo de ingestão e estimularam movimentos mastigatórios mais verticais, promovendo alterações no desgaste dentário (Baker, 2002). As PEED formam-se, respectivamente, nas bordas bucal e lingual da superfície oclusal dos dentes pré-molares e molares maxilares e mandibulares, devido à anisognatia, aumentando o ângulo de oclusão dos dentes pré-molares e molares.

As PEED causam, freqüentemente, ulcerações na bochecha e língua, com conseqüente dor à mastigação e mudança da sua biomecânica (Lane, 1994). A mastigação deficiente leva à trituração insuficiente dos alimentos e à diminuição da produção de saliva, o que pode afetar a digestibilidade dos alimentos e o trânsito intestinal (Meyer, 1995; Mueller, 1991). Ralston et al. (2001) estudaram a influência das PEED e dos ganchos na digestibilidade da matéria seca (MS), proteína bruta (PB), fibra em detergente neutro (FDN) e fibra em detergente ácido (FDA) em eqüinos de sete a 18 anos de idade submetidos a dois tipos de desgaste dentário corretivo e não encontraram diferença significativa após o tratamento, o que foi atribuído à alteração dentária pouco expressiva nos eqüinos avaliados.

O objetivo do presente trabalho foi avaliar a influência das pontas excessivas de esmalte dentário na digestibilidade de nutrientes da dieta de eqüinos.

\section{MATERIAL E MÉTODOS}

Utilizaram-se 13 eqüinos na faixa etária de cinco a oito anos, sendo nove machos castrados e quatro fêmeas não gestantes, hígidos, desverminados e com peso corporal de $450,46 \pm 18,02 \mathrm{~kg}$ e escore corporal 3 (Spiers, 1999). Os eqüinos pertenciam ao Regimento de Cavalaria da PMMG e eram utilizados no policiamento urbano em escala de seis horas diárias. Tinham arcadas dentárias completas, com pontas excessivas de esmalte dentário, porém sem histórico de alterações alimentares ou tratamento dentário. A alimentação consistiu de capim-elefante picado (Pennicetum purpureum) e ração concentrada ${ }^{1}$, oferecidos em seis refeições diárias em quantidade igual ou superior às recomendadas pelo Nutrient... (1989). A água e o sal mineral ${ }^{2}$ foram fornecidos à vontade.

O período experimental foi dividido em quatro fases. Na primeira (F1), foi realizada a adaptação ao marcador óxido crômico, utilizado para a estimativa da produção fecal. Foram utilizados $5 \mathrm{~g}$ diários do marcador, embalados em papel toalha, sendo o conjunto embebido em melado de cana no momento do fornecimento para proporcionar palatabilidade e evitar perdas do óxido crômico. $\mathrm{O}$ marcador foi oferecido às $5 \mathrm{e}$ 13 horas, com um período de adaptação de 10 dias, segundo Saliba $(2003)^{3}$. A adaptação à dieta não foi necessária, pois, durante o experimento, foram utilizados os mesmos alimentos usados no dia-a-dia dos eqüinos.

\footnotetext{
${ }^{1}$ Nutriage 15 - Mogiana alimentos S.A. Além Paraíba - MG

${ }^{2}$ Sal Mineral Socil Pró-Pecuária S. A. Brasil.

${ }^{3}$ Saliba, E.O.S. (2003) - Comunicação pessoal. EV/UFMG
} 
A segunda (F2) consistiu na primeira colheita de fezes, após o período de adaptação ao marcador, e foi conduzida de modo semelhante para a fase quatro (F4), que ocorreu 14 dias após o tratamento dentário. Em F2 e F4, as fezes foram colhidas diretamente do reto dos animais durante cinco dias, às 5 e 13 horas, nos tempos equivalentes ao oferecimento do marcador. As amostras de alimento foram colhidas em igual número, porém a partir de três dias antes do início da colheita de fezes. As amostras de fezes e de alimento foram acondicionadas em sacos de polietileno e conservadas a $-20^{\circ} \mathrm{C}$.

A terceira (F3) correspondeu ao denominado período de passagem, com início após o tratamento e término no início da segunda colheita de fezes (F4). A F3 durou 14 dias, seguindo o tempo recomendado por Ralston et al. (2001) para a adaptação a dietas ou a mudanças perceptíveis na digestibilidade dos nutrientes após o desgaste dentário corretivo em eqüinos.

O tratamento consistiu no desgaste corretivo das pontas excessivas de esmalte dentário com os eqüinos contidos em tronco apropriado e sob efeito da associação de $0,06 \mathrm{mg} / \mathrm{kg}$ de romifidina ${ }^{4}$ e $0,03 \mathrm{mg} / \mathrm{kg}$ de butorfanol ${ }^{5}$. O material utilizado para o desgaste corretivo foi um abre-boca tipo Hausmmam $^{6}$, uma grosa elétrica ${ }^{7}$ e uma grosa manual $^{8}$ reta.

Para a determinação da digestibilidade aparente da MS, PB, FDN, FDA, hemicelulose e celulose e para a quantificação de óxido crômico nas fezes, foram seguidas as recomendações de Silva (1990).

Durante o período experimental, as sobras de alimento foram pesadas e o comportamento alimentar foi avaliado em igual número de observações por eqüino com o registro do número de mastigações por minuto e do tempo de ingestão por quilograma de alimento. Os eqüinos foram pesados seis vezes, no início do experimento e em intervalos semanais. $\mathrm{O}$ delineamento experimental foi inteiramente ao

\footnotetext{
${ }^{4}$ Sedivet. Boehringer Ingelheim do Brasil. Itapecerica da Serra - SP

${ }^{5}$ Torbugesic. Fort Dodge Saúde Animal. Campinas - SP.

${ }^{6}$ Alberts Dental Supply. Loundville, NY. EUA.

${ }^{7}$ Dremel. Model 732. Racine, Wisconsin. EUA.

${ }^{8}$ Paselin. Paris, França.
}

acaso, com dois tratamentos (antes e após desgastes das pontas excessivas do esmalte dentário) e seis repetições. $\mathrm{O}$ peso vivo nos seis períodos foi comparado pelo teste Duncan a 5\% de probabilidade. As digestibilidades da MS, PB, FDN, FDA, hemicelulose e celulose foram comparadas pelo método de comparação de pares.

\section{RESULTADOS E DISCUSSÃO}

Os tempos de ingestão foram de $18 \pm 6$ minutos por quilo para o volumoso e de $20 \pm 5$ minutos por quilo para o concentrado e não se alteraram com o tratamento. Esses tempos foram superiores aos citados por Meyer (1995), o que permite afirmar que os eqüinos alimentaram-se por mais tempo. Estes resultados contrariam as expectativas devido à aparente agitação demonstrada pelos animais nos momentos que precediam às refeições ou mesmo durante o seu fornecimento. Mantidos em ambiente de cavalaria militar sob regime de confinamento intensivo e com horários fixos de refeição, esse comportamento foi mais acentuado durante o fornecimento do alimento concentrado.

O tempo de ingestão do concentrado foi superior ao do volumoso, diferente do que foi observado por Meyer (1995). Acredita-se que isso tenha ocorrido pelo fato de o capim ter sido fornecido picado, o que pode ter facilitado a preensão de quantidade proporcionalmente maior de capim em relação à de concentrado.

A freqüência de mastigações foi de $95 \pm 10$ movimentos por minuto para o volumoso e alimento concentrado, não se modificando após o tratamento. A freqüência encontrada está de acordo com o observado em eqüinos sem alterações dentárias (Baker, 2002). Os eqüinos deste experimento não apresentavam lesões orais, o que pode significar que, mesmo possuindo PEED, essas pareciam não provocar dor ou incômodo suficientes para reduzir a freqüência mastigatória dos eqüinos. A invariabilidade após o tratamento reforça essa justificativa. 
Houve aumento da digestibilidade $(\mathrm{P}<0,001)$ para todas as variáveis após o tratamento dentário (Tab. 1). Os valores foram maiores para PB e EB, que são os constituintes do alimento de maior biodisponibilidade (Van Soest, 1993). Com relação aos constituintes da parede celular, o maior índice para a hemicelulose está em concordância com a maior capacidade dos eqüinos em aproveitar esse carboidrato estrutural (Van Soest, 1993). As hemiceluloses estão unidas à lignina por meio de ligações ésteres cruzadas que podem ser rompidas pela mastigação $\left(\right.$ Saliba, 2003) ${ }^{3}$. Como o eqüino apresenta melhor capacidade de digerir as hemiceluloses, seu aumento foi superior ao dos outros constituintes da parede celular. Esse aumento sugere que o desgaste corretivo das PEED influenciou positivamente a mastigação, melhorando a eficiência do rompimento das ligações ésteres da lignina e das hemiceluloses, promovendo sua disponibilidade aos processos digestivos.

Tabela 1. Média, desvio-padrão e índice de significância $(\mathrm{P})$ da digestibilidade aparente (em $\%)$ da matéria seca (MS), proteína bruta (PB), energia bruta $(\mathrm{EB})$, fibra em detergente neutro (FDN), fibra em detergente ácido (FDA), hemicelulose (HEMICEL) e celulose (CEL) obtidos antes (F1) e após o tratamento de desgaste corretivo (F2) em eqüinos com pontas excessivas de esmalte dentário

\begin{tabular}{lccc}
\hline Variável & F1 & F2 & Valor de p \\
\hline MS & $66,44 \pm 2,27$ & $75,48 \pm 1,47$ & $4,93 \times 10^{-6}$ \\
PB & $75,04 \pm 2,69$ & $83,80 \pm 1,66$ & $6,33 \times 10^{-6}$ \\
EB & $66,42 \pm 2,43$ & $75,00 \pm 1,34$ & $1,19 \times 10^{-5}$ \\
FDN & $60,19 \pm 2,69$ & $69,81 \pm 1,74$ & $2,45 \times 10^{-5}$ \\
FDA & $57,22 \pm 2,68$ & $65,80 \pm 2,06$ & $5,53 \times 10^{-6}$ \\
HEMICEL & $62,81 \pm 3,11$ & $73,92 \pm 1,48$ & $6,33 \times 10^{-6}$ \\
CEL & $65,69 \pm 2,22$ & $72,04 \pm 1,41$ & $1,25 \times 10^{-4}$ \\
\hline
\end{tabular}

O aumento nos índices de digestibilidade dos carboidratos estruturais permite supor que, além da melhoria na trituração e exposição desses compostos aos processos digestivos, ocorreu também maior aproveitamento da forragem como fonte energética.
Não houve diferença significativa do peso corporal ao longo do período experimental, bem como do escore corporal, dentro da escala descrita por Spiers (1999). As PEED, apesar de afetarem significativamente a digestibilidade, não foram suficientes para alterar essas variáveis inter-relacionadas. Tal fato pode ter sido motivado pelo curto período do experimento e, principalmente, pela elevada proporção de alimento concentrado em relação ao volumoso, oferecida antes do início do experimento, superior à recomendada pelo Nutrient... (1989). A proporção de alimento concentrado e volumoso utilizada durante o experimento (5:5) seguiu as recomendações do Nutrient... (1989). No entanto, é importante ressaltar que nem sempre ocorre perda de peso e queda de escore corporal em eqüinos com alterações dentárias, a menos que elas sejam severas e crônicas (Dixon, 2003).

Os resultados apontam para a importância das alterações dentárias na digestibilidade dos nutrientes, mesmo em eqüinos sem alterações orais e com escore corporal adequado. Tentou-se isolar a principal e mais freqüente alteração dentária dos eqüinos, utilizando-se animais na faixa etária em que as PEED são mais significativas, e evitou-se a interferência de outras alterações dentárias clinicamente perceptíveis ou não. A diferença entre os resultados desta pesquisa e os de Ralston et al. (2001) pode ser atribuída às variações metodológicas e de delineamento experimental, que incluem a seleção dos animais. Neste experimento, optou-se por utilizar eqüinos de faixa etária mais estreita e somente com PEED, visando controlar melhor as variações individuais relativas à digestibilidade, bem como as interferências de outras alterações dentárias e de tecidos peridentários, às quais os eqüinos mais velhos estão mais predispostos.

\section{CONCLUSÕES}

O desgaste corretivo das pontas excessivas de esmalte dentário aumenta a digestibilidade dos nutrientes de dietas de eqüinos e limita a digestibilidade dos nutrientes da dieta, mesmo em eqüinos sem lesões orais e com escore corporal adequado. 


\section{REFERÊNCIAS BIBLIOGRÁFICAS}

AKIN, D.E. Histological and physical factors affecting digestibility of forages. Agron. J., v.81, p.17-25, 1989.

BAKER, G.J. Dental physiology. In: EASLEY, K.J.; BAKER, G.J. Equine dentistry. London: W.B. Saunders, 2002. p.29-34.

BRIGHMAM, E.J.; DUNCANSON, G.R. An equine postmortem dental study: 50 cases. Equine Vet. Educ., v.12, p.59-62, 2000.

DIXON, P.M. Removal of equine dental overgrowths. Equine Vet. Educ., v.12, p.68-81, 2000.

DIXON, P.M. The aetiology, diagnosis and current therapy of developmental and acquired equine dental disorders. In: CONGRESS ON EQUINE MEDICINE AND SURGERY, 8., 2003, Ithaca. Proceedings... Ithaca: IVISO, 2003. Disponível em: <www.ivis.org>. Acessado em: 29/04/04.

DIXON, P.M.; TREMAINE, W.H.; PICKLES, K. et al. Equine dental disease: a long-term study of 400 cases: Part III - Disorders of wear, traumatic damage, other fractures, tumours and miscellaneous disroders of te cheek teeth. Equine Vet. J., v.32, p.9-18, 2000.

LANE, J.G. A review of dental disorders of the horse, their treatment and possible fresh approaches to management. Equine Vet. Educ., v.6, p.13-21, 1994.

MEYER, H. Bases anatômicas e fisiológicas. In: Alimentação de cavalos. São Paulo: Varela, 1995. p.33-62.

MUELLER, E.P. O. Equine dental disease: cause, diagnosis and treatment. Comp. North Am. Educ., v.13, p.1451-1461, 1991.

NUTRIENT requirements of equine. 5.ed. Washington: NAS, 1998. 100p.

RALSTON, S.L.; FOSTER, D.L.; DIVERS, T. et al. Effect of dental correction on feed digestibility in horses. Equine Vet. J., v.33, p.390-393, 2001.

SILVA, D.J. Análise dos alimentos. Viçosa: Imprensa Universitária, 1990. p.165.

SPIERS, V.C. Exame clínico de eqüinos. Porto Alegre: Artmed, 1999. p.366.

VAN SOEST, P.J. Nutritional ecology of the ruminant. Ithaca: Comstock Publishing Associates, 1993. 476p. 